\title{
ANALISIS TEKNIK SEGMENTASI PADA PENGOLAHAN CITRA
}

\author{
Mira Orisa ${ }^{1}$, Taufik Hidayat ${ }^{2}$ \\ ${ }^{1)}$ Teknik Informatika, Institut Teknologi Nasional Malang \\ ${ }^{2)}$ Teknik Elektro, Institut Teknologi Nasional Malang \\ mira_orisa@lecturer.itn.ac.id
}

\begin{abstract}
ABSTRAK
Pengolahan citra digital merupakan bidang ilmu yang banyak diaplikasikan dalam bidang kedokteran untuk mendeteksi citra tertentu seperti citra kanker, citra tumor dari citra medis. Banyak penelitian yang sudah dilakukan dari tahun 2010 hingga 2019. Penelitian membahas proses segmentasi pada pengolahan citra digital. Dari beberapa metode dalam melakukan segmentasi citra digital maka dalam penelitian ini membahas metode thresholding dan metode transformasi hough. Dimana kedua metode tersebut memiliki kelebihan masing-masing dan juga saling melengkapi dalam proses pengolahan citra digital.metode thresholding berguna untuk memisahkan objek-objek dalam citra menjadi dua nilai yaitu hitam dan putih. Hasil citra pada proses segmentasi menggunakan metode thresholding bergantung pada nilai ambangnya. Perlu kejelian dalam menentukan nilai ambang agar citra hasil segmentasi dapat mencuplik objek yang diinginkan dalam citra. Sedangkan transformasi hough dapat mendeteksi objek garis atau objek lingkaran. Penerapan segmentasi transformasi hough ini lebih tepat diterapkan pada aplikasi mendeteksi bentuk. Pada metode transformasi hough yang perlu diperhatikan adalah jari-jari lingkaran dalam 1 piksel serta array akumulatornya. Pencarian dilakukan berdasarkan kemungkinan hubungan atau garis yang ada.
\end{abstract}

Keyword : citra, thresholding, transformasi hough, operator canny

\section{PENDAHULUAN}

Kebaharuan teknologi di bidang pengolahan citra banyak diterapkan ke dalam bidang kedokteran seperti penelitian yang dilakukan oleh rais dan diana pada tahun 2018 tentang Segmentasi Citra Tumor Otak Mengunakan Support Vector Machine. pada penelitian ini Teknik segmentasi digunakan untuk menentukan posisi tumor pada citra tumor otak. Citra tumor otak terlebih dahulu dihilangkan noisenya dengan metode wiener filte. Kemudian dilakukan pengklasifikasinan menggunakan Support Vector Machine. Sehingga pada penelitian ini dapat mendeteksi tumor otak pada citra tumor otak yang serigkali sulit untuk melihatnya secara kasat mata.[1]

Segmentasi citra menggunakan algoritma KMeans dilakukan oleh Kusuma dan Ellyana pada tahun 2018 dalam judul penelitiannya yaitu Penerapan Citra terkomresi pada Segmentasi Citra Menggunakan Algoritma K-Means.. Citra yang diolah adalah citra MRI otak dan citra payudara. Sebelum citra-citra tersebut disegmentasi sebelumnya dikompresikan terlebih dahulu. Pada penelitian ini menghasilkan kesimpulan bahwa jenis-jenis ekstensi citra yang menjadi input aplikasi K-Means.dimana citra yang berekstensi BMP yang memakan waktu lama dalam proses segmentasi. Sedangkan citra yang berekstensi JPG yang paling cepat.[2]

Seperti penelitian yang dilakukan oleh Andika dan Hafiz pada tahun 2018 menggunakan segmentasi citra menggunakan K-Means dan Fuzzy C-Means. Pada penelitian ini membandingkan ke dua metode tersebut. Menurut hasil penelitian saudara Andika dan Hafiz bahwa metode K-means lebih baik daripada metode fuzzy C-means.[3]

Ada juga yang menggunakan metode thresholding untuk segmentasi citra. Hal ini ditunjukkan pada penelitian yang dilakukan oleh Maria dkk pada tahun 2018. Penelitian mereka diberi judul segmentasi citra digital bentuk daun pada tanaman politani samarinda menggunakan metode thresholding. Segmentasi citra daun dilakukan menggunakan metode thresholding sehingga akan mengidentifikasi golongan daun berdasarkan bentuk tulang daun.[4]

Segmentasi citra obyek buah menggunakan ohta colour space dan niblack adaptive local thresholding. Penelitian tersebut dilakukan oleh saudara Pangarso dan Kusumaningrum pada tahun 2019. Permsalahan yang dihadapi pada penelitian ini adalah segmentasi objek berbasis OHTA. dimana masih terdapat bayangan atau ganguan pada citra objek buah. Sehingga diatasi dengan menggunakan metode Niblack adaptive local Thresholding. Metode yang diterapkan pada penelitian ini dapat meningkatkan akurasi citra output.[5]

Penelitian yang dilakukan oleh Kumaseh dkk tahun 2013 pernah juga melakukan penelitian untuk segmentasi citra dengan metode thresholding. Objek citra yang diteliti adalah citra ikan. Untuk mendapatkan objek yang diinginkan pada citra ikan ,setalah dilakukan proses segmentasi maka citra tersebut akan diolah dengan proses deteksi tepi menggunakan operator canny dan untuk penajaman citra dilakukan dilasi.[6]

Pada tahun 2012 Nasution pernah melakukan penelitian dengan judul segmentasi citra digital 
berbasis clustering menggunakan deteksi tepi. Objek yang diteliti adalah kubus,balok, dan bola. Objek dikenali meggunkan operator sobel.[7]

Dari sekian banyak banyak metode segmentasi yang pernah ditelita, maka pada penelitian ini akan menganalisis 2 metode segmentasi citra. Kami mengharapkan supaya bias berkontribusi terhadap kajian ilmu di bidang pengolahan citra digital khususnya mengkaji metode segmentasi.

\section{METODE PENELITIAN}

\subsection{Segmentasi Citra}

Teknik untuk membagi atau memisahkan citra ke dalam beberapa daerah (region) berdasarkan kemiripan atribut yang dimilikinya disebut dengan segmentasi[13]. segmentasi juga disebut sebuah proses yang membagi sebuah citra menjadi sejumlah bagian atau objek. Segmentasi bukanlah proses tungal yang dilakukan dalam pengolahan citra digital. Namun segmentasi merupakan proses yang penting dalam pengolahan citra digital. Pada proses segmentasi objek yang menjadi target akan diambil untuk proses selanjutnya. Ada dua karakteristik nilai derajat kecerahan citra pada Teknik segmentasi ini, yaitu discontinuity dan similarity. Pada discontinuity, citra dipisah pisah berdasarkan perubahan yang mencolok dari derajat kecerahannya, biasanya diterapkan pada deteksi tepi, garis, area dan sisi citra. Sedangkan pada similarity citra akan dipisah berdasarkan thresholding, region growing dan region spiltting dan merging, biasanya diterapkan pada citra yang statis dan dinamis.[5]

\subsection{Transformasi hough}

Metode transformasi hough merupakan sebuah metode yang memisahkan antara objek dan background dengan penentuan batas-batas objek tersebut dalam sebuah citra. Tujuan dari transformasi ini adalah untuk mendapatkan suatu fitur yang lebih spesifik karena metode ini dapat mendeteksi sebuah tepian dengan celah pada batas fitur dan tidak dipengaruhi oleh derau. Misalkan mendeteksi garis, lingkaran,elips dan parabola. Adapun rumus yang digunakan pada transformasi hough bergantung pada jenis objek yang dicari.[13]

Untuk mencari objek garis menggunakan rumus[13].

$$
x \cos \theta+y \sin \theta=r .
$$

Dimana $\mathrm{x}$ dan $\mathrm{y}$ merupakan titik koordinat objek. Sedangkan $\theta$ adalah sudut yang dibentuk antara objek garis dengan sumbu $\mathrm{x}$. $\mathrm{r}$ adalah jarak antara garis dengan pusat $(0,0)$.

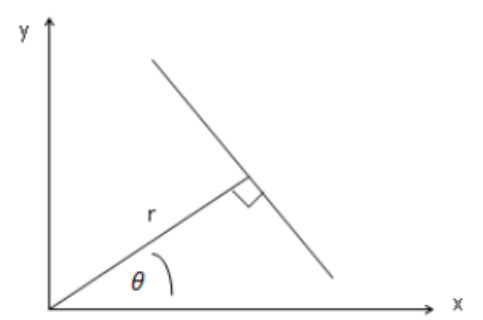

Gambar 1. deskripsi parametric garis lurus[13]

Untuk mencari objek lingkaran menggunakan rumus.[13]

$$
\left(x-x_{0}\right)^{2}+\left(y-y_{0}\right)^{2}=r^{2} \text {. }
$$

Perhitungan objek lingkaran lebih kompleks mengunakan parameter $3 \mathrm{D}\left(x_{0}, y_{0}, r\right)$. $x_{0}$ dan $y_{0}$ koordinat pusat lingkaran dan $r$ adalah jari-jari lingkaran.

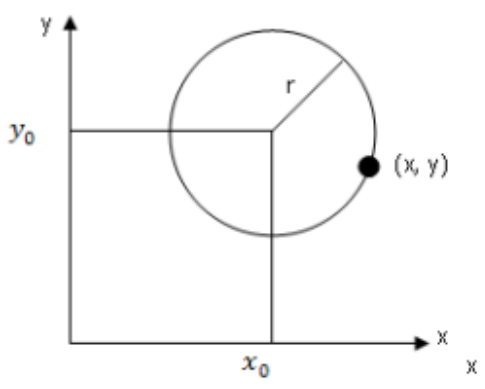

Gambar 2. deskripsi parametric lingkaran.[13]

Ada beberapa tahap yang dilakukan oleh algoritma transformasi hough dalam mendeteksi sebuah lingkaran. Pertama akan dilakukan proses deteksi tepi bisa mengunakan operator Robert cross , operator canny atau operator sobel. Setelah titik tepi didapat maka algoritma transformasi hough akan bekerja pada titik tersebut. Transformasi lingkaran hough akan membentuk lingkaran sepanjang tepian yang ditemukan sebasar r.. kemudian dicari daerah yang paling banyak dilewati garis yang akan di jadikan titik tengah citra yang akan dicari. Transformasi hough menggunakan sebuah akumulator. Akumulator ini merupakan deretan array yang memiliki dimensi yang berbeda-beda tergantung dari jumlah parameter objek yang dicari.[13]

\subsection{Thresholding}

Salah satu Teknik segmentasi citra digital adalah thresholding. Thresholding mengubah citra skala keabuan menjadi citra biner. Metode ini melakukan pengaturan nilai ambang sedemikian rupa sehingga citra dapat tersegmentasi. Dengan kata lain dilakukan pemanipulasian nilai kemudian meninjau

hasil thresholding sampai segmentasi yang memuaskan tercapai. Ambang batas dapat digunakan untuk mengelompokkan citra jika objek terang tertanam dalam citra yang lebih gelap. 
Poin utama dalam metode ini adalah ketepatan dalam memilih nilai ambang batas. Ada banyak metode yang digunakan dalam industri ini yang meliputi pengelompokan k-means, varians maksimum yang disebut sebagai metode Otsu atau entropi maksimum metode. Sekarang metode tertentu telah dikembangkan dimana gambar Tomografi Terkomputasi dapat ambang batas yang mencakup ambang batas yang berasal dari radiografi dan bukan citra yang direkonstruksi.[14]

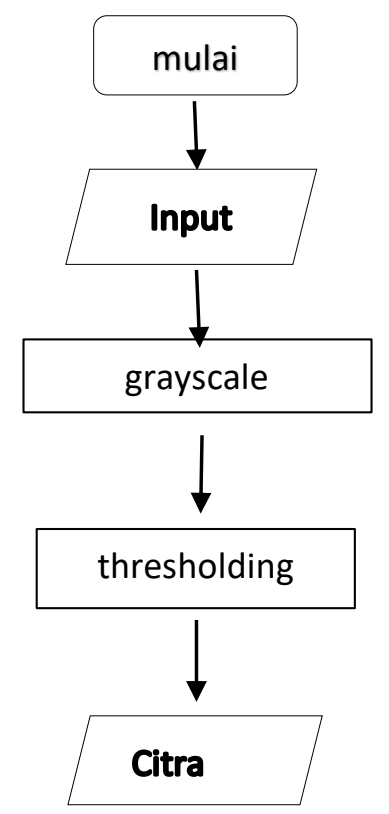

Gambar 3. Flowchart proses segmentasi citra digital
Citra yang menjadi inputan adalah citra warna. Sebelum dilakukan proses segmentasi maka citra tersebut akan diubah menjadi citra grayscale terlebih dahulu. Kemudian proses segmentasi baik dengan metode thresholding.

\section{HASIL DAN PEMBAHASAN}

3.1. Hasil Pengujian Segmentasi Menggunakan metode transformasi hough

Segmentasi mengunakan metode transformasi hough biasanya digunakan untuk mendeteksi bentuk garis atau lingkaran. Pada citra berikut yang terdeteksi adalah citra yang berbentuk lingkaran. Untuk mendapatkan objek yang diinginkan maka perlu diketahui jari-jari di kisaran berapa. Pada penelitian ini untuk mendeteksi koin yang ada pada citra maka ditentukan jari-jari dari 60 hingga 120 piksel, dalam langkah 1 piksel. Untuk menghindari bias agar dapat menemukan lingkaran yang lebih besar maka opsi yang dipilih pada coding adalah

$\mathrm{h}=$ circle_hough(e, radii, 'same', 'normalise'); untuk menemukan peaks di akumulator maka digunakan metode neighbourhood-suppression untuk memastikan bahwa lingkaran yang didapat adalah lingkaran yang terpisah secara spasial. Pada penelitian ini ditentukan peaks nya adalah 10 peaks, 10 peaks inilah yang terlihat menonjol. Pada saat program dijalankan akan ditemukan 10 koin .

peaks = circle_houghpeaks (h, radii, 'nhoodxy', 15, 'nhoodr', 21, 'npeaks', 10);

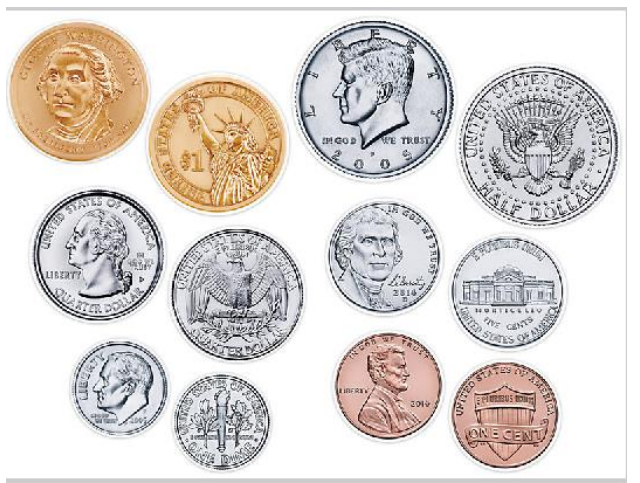

a

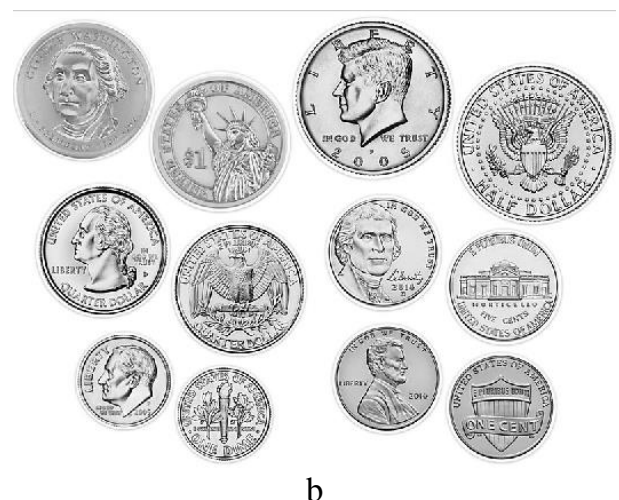

b 

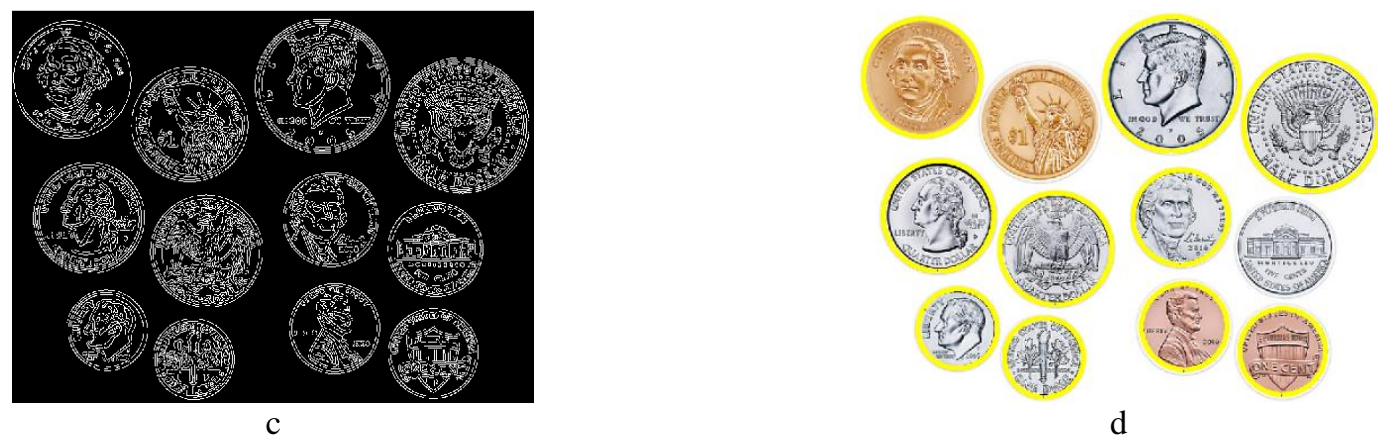

Gambar 4. a) citra asli b) citra grayscale.c) citra hasil proses deteksi tepi canny.d) citra hasil segmentasi transformasi hough. (sumber image: www.lakeshorelearning.com)

\subsection{Hasil Pengujian Segmentasi Mengunakan metode thresholding}

Citra output yang dihasilkan oleh metode thresholding mengalami perubahan tingkat iluminasi sesuai dengan besar kecilnya nilai ambang atau nilai $\mathrm{T}$ yang ditentukan. Adapun kisaran besaran nilai ambang/nilai $\mathrm{T}$ adalah dari 0 hingga
255. Semakin mendekati 0 atau semakin mendekati 255 maka objek akan susah dibedakan dengan background. Sebaiknya jika menggunakan metode thresholding maka harus bias mendapatkan nilai ambang yang tepat agar objek citra bisa dipisahkan dengan background. Nilai ambang yang digunakan pada penelitian ini yaitu $\mathrm{T}=50,100,150$, dan 255 .
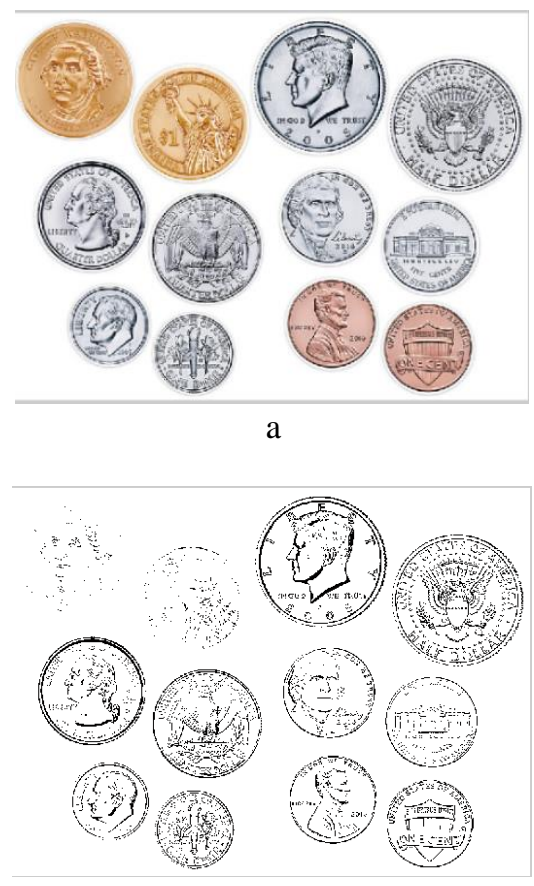

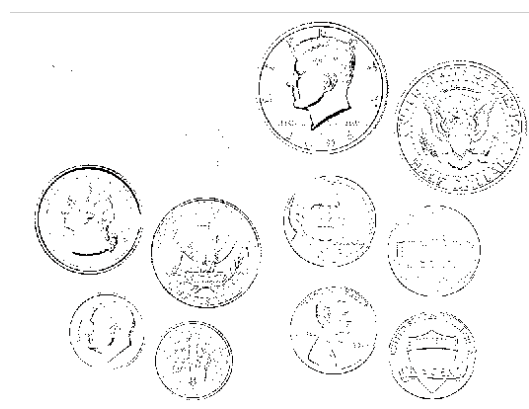

b

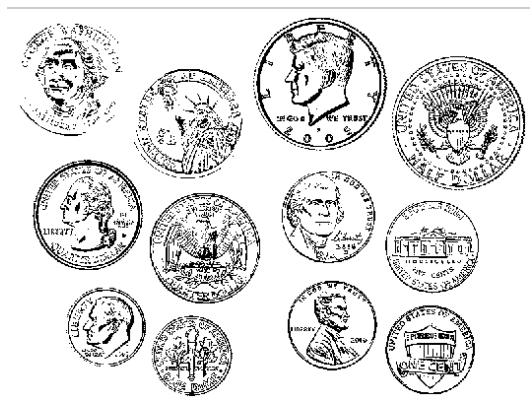

$d$

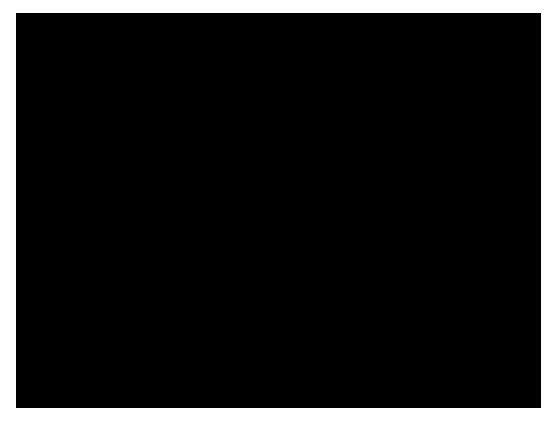

e

Gambar 5. a) citra asli b) citra hasil thresholding $T=50 . c$ ) citra hasil thresholding $T=100 . d$ ) citra hasil thresholding $\mathrm{T}=150$.e) citra hasil thresholding $\mathrm{T}=255$

(sumber image: www.lakeshorelearning.com) 


\section{KESIMPULAN}

Citra yang dihasilkan oleh tiap metode memiliki karakteristik yang berbeda. Untuk metode thresholding, citra yang dihasilkan adalah citra biner. Walaupun citra yang kita inputkan adalah citra warna (citra RGB) namun pada proses segmentasi terjadi proses pengambangan citra grayscale. Proses pengambangan citra grayscale menghasilkan citra hitam putih. Baik atau buruknya kualitas citra yang dihasilkan pada metode ini bergantung pada nilai ambang. Citra berwarna putih disebabkan oleh nilai intensitas citra melebihi atau sama dengan nilai ambangnya. sedangkan citra hasil yang bewarna hitam diakibatkan karna nilai intensitas citra lebih kecil dari nilai ambang. Metode thresholding dan metode transformasi hough adalah metode-metode dalam proses segmentasi citra digital. Namun demikian penerapannya berbeda. Metode transformasi hough digunakan untuk mendeteksi garis dan lingkaran yang terdapat pada citra digital. Segmentasi menggunakan metode ini berdasarkan hubungan ketetanggaan antara pikselpiksel yang ada pada citra menggunakan sebuah persamaan. Persamaan yang ada di transformasi hough yaitu persamaan garis lurus untuk mendeteksi garis dan persamaan lingkaran untuk mendeteksi lingkaran.

\section{DAFTAR PUSTAKA}

[1]. Rais. Amin Nur \& Dwiza Riana. 2018. segmentasi citra tumor otak menggunakan support vector machine classifier. seminar nasional inovasi dan tran (SNIT). ISBN:978602-61268-5-6

[2]. Kusuma.I Wayan Angga Wijaya \&Rossy Lydia Ellyana. 2018. penerapan cira terkompresi pada segmentasi citra menggunakan algorita K-Means.JUTEI edisi volume 2 No.1.ISSN: 2579-3675. eISSN:2579-5538

[3]. Andika.Tahta Herdian \& Aliy Hafiz. 2018. analisis perbandingan segmentasi citra menggunakan metode K-means dan fuzzy Cmeans. seminar nasional teknologi dan bisnis.

[4]. Maria.Eny.,Yulianto., Yunita putri arinda.,Jumiaty \& palma nobel. 2018. segmentasi citra digital bentuk daun pada tanaman di politani samarinda menggunakan metode thresholding. JURTI Vol.2 No.1.ISSN:2579-8790.
[5]. Pangarso.Gayuh \& Retno Kusumaningrum. 2019. segmentasi citra objek buah menggunakan ohta colour space dan niblack adaptive local thresholding. seminar nasional teknologi informasi dan komunikasi (SENTIKA). ISSN:2089-9815.

[6]. Kumaseh.Max R ., Luther Latumakulita \& Nelson Nainggolan.2013.segmentasi citra digital ikan menggunakan metode thresholdingJurnal ilmiah sains Vol.13 No.1.

[7]. Nasution. Torkis. 2012. Segmentasi citra digital berbasis clustering menggunakan deteksi tepi sobel. jurnal sains dan teknologi informasi Vol.1 No.2.

[8]. Doneva.Chairunnisya., Bambang hidayat \& achmad rizal. 2013. identifikasi jenis jerawat berdasarkan kombinasi segmentasi warna dan analisis tekstur dengan deteksi binary large object (BLOB) menggunakan jaringan syaraf tiruan-learning vector quantization. 2013. tugas akhir. universitas Telkom.

[9]. Putra.I ketut Gede Darma \& I gede Suarjana. 2010. segmentasi citra retina digital retinopati diabetes untuk membantu pendeteksi mikroaneurisma. teknologi elektro.Vol.9.No.1.

[10]. Basyid.Fakhrurrozi \& Kusworo adi. 2016. segmentasi citra medis untuk pengenalan objek kanker menggunakan metode active counter. Youngster Physics Journal.ISSN:2302-7371.

[11]. Witeti. 2011. identifikasi sel kanker prostat menggunakan metode segentasi berdasarkan ukuran objek pada citra. tesis. Jurusan Teknik Elektro Fakultas Teknik Universitas Diponegoro.

[12]. Achmad.Balza \& Kartika Firdausy.2005. teknik pengolahan citra digital menggunakan delphi. ISBN:979-98276-5-5. penerbit ardi publishing. yogyakarta.

[13]. Putra. Darma. 2010. pengolahan citra digital. penerbit andi. yogyakarta.

[14]. Verma.Neha \& Deepak sharma. 2013. region merging based image segmentation using maximalsimilarity mechanism. internasional journal of engineering research and development. e-ISSN:2278-067X. p-ISSN: 2278-800x.Vol.7. issue.7.

[15]. https://www.lakeshorelearning.com/products/ classroomdecorations/accents/us-coinaccents/p/DD139/. 